\title{
Subnormal activation of phagocytes by complement in chronic inflammatory bowel disease? Neutrophil chemotaxis to complement split product C5a
}

\section{J ELMGREEN}

From the Medical Gastroenterological Department C, Herlev Hospital, University of Copenhagen, Copenhagen, Denmark

SUMMARY The capacity of circulating phagocytes for activation by complement was investigated in consecutive, untreated cases of chronic inflammatory bowel disease. The major complement derived chemotactic factor, C5a, served as chemoattractant in dose response studies of neutrophil chemotaxis. A similar, significantly decreased sensitivity and peak response was revealed in patients with Crohn's disease and ulcerative colitis. This subnormal function of neutrophils could be shown even in cases of complete clinical remission. Chemotactic response to casein and spontaneous motility was within the normal range showing an unaffected basic cell function of neutrophils in the patients. The study shows a dysfunction of phagocytic cells, related to potentially important phlogistic mediators, in chronic inflammatory bowel disease.

Hypercatabolism of complement has been revealed in chronic inflammatory bowel disease (IBD) by studies of the third component $\mathrm{C} 3$, which occupies a key position in cascade reactions involving both the classical and alternative pathway. ${ }^{1}$ An increased fractional catabolic rate of this component ${ }^{2}$ appears to be associated with raised concentrations of circulating C3 split products. ${ }^{3}$ Furthermore, indirect evidence for continuing activation of complement in IBD has been forwarded by investigations of immunoconglutinins. Such antibodies to activated complement components have been shown in increasing titres with increasing length of disease history. ${ }^{4}$ Activation of complement in vitro leads to utilisation of $\mathrm{C} 3$, correlating positively to release of the split product $\mathrm{C} 5 \mathrm{a}$ from the native complement component $\mathrm{C} 5$ in normal subjects and IBD patients. ${ }^{5}$ These results are consistent with an activation of neutrophil functions by C5a in IBD patients.

The aim of our study was to investigate the migratory response of isolated neutrophils by specific activation with C5a. Chemotaxis to the complement independent chemoattractant casein has previously been investigated in IBD..$^{5-7}$ This

Address for correspondence: Jens Elmgreen, MD, Medical Department C 107. Herlev University Hospital, DK-2730 Herlev, Denmark.

Received for publication 19 September 1983 non-physiologic activator was included in all the present tests to study the basic cell function.

\section{Methods}

PATIENTS

Consecutive outpatients, 15 with Crohn's disease and 15 with ulcerative colitis were studied. Patients who had been treated medically within the three preceding months were excluded. The diagnostic criteria applied have previously been published. ${ }^{8}$ Eight of the Crohn's disease patients had the diagnosis confirmed by histology. None of the ulcerative colitis patients had been colectomised and all had involvement of a substantial part of colon proximal to the rectum.

Assessment of disease activity ${ }^{9}{ }^{10}$ revealed that approximately half the patients were in a complete clinical remission. None of the active cases had systemic reactions such as fever or loss of weight. Extraintestinal complications included arthritis in two of the Crohn's disease patients. Clinical parameters are shown in Table 1.

An age matched group of 15 healthy volunteers served as control subjects (Table 1). Informed consent was obtained from all participants.

REAGENTS

Casein (alkalilöslich, Merck, Darmstadt, FRG), 
Table 1 Clinical parameters of IBD patients

\begin{tabular}{|c|c|c|c|c|c|c|c|c|c|}
\hline \multirow[b]{2}{*}{ Group } & \multirow[b]{2}{*}{ No } & \multirow[b]{2}{*}{$\begin{array}{l}\text { Age* } \\
(y r)\end{array}$} & \multirow[b]{2}{*}{ Sex } & \multirow[b]{2}{*}{$\begin{array}{l}\text { Duration* } \\
\text { (yr) }\end{array}$} & \multicolumn{2}{|c|}{ Disease activity } & \multicolumn{3}{|c|}{ Disease involvement } \\
\hline & & & & & Quiescent & Active & lleum & $\begin{array}{l}\text { Ileum }+ \\
\text { colon }\end{array}$ & Colon \\
\hline Crohn's disease & 15 & $34(20-68)$ & $9 \mathrm{~F}, 6 \mathrm{M}$ & $6(()-17)$ & 4 & 11 & 8 & 5 & 2 \\
\hline Ulcerative colitis & 15 & $40(27-63)$ & $6 \mathrm{~F}, 9 \mathrm{M}$ & $9(0-22)$ & 8 & 7 & - & - & 15 \\
\hline Healthy volunteers & 15 & $36(23-60)$ & $7 \mathrm{~F}, 8 \mathrm{M}$ & & & & & & \\
\hline
\end{tabular}

* Median value, range in parantheses.

epsilon aminocaproic acid (Meco Benzon, Copenhagen, Denmark), ethylene diaminetetraacetate (EDTA) (Merck), $3 \mu \mathrm{m}$ pore size filters (Sartorius, Göttingen, FRG), human albumin purified (Behringwerke, Marburg, FRG), methylcellulose (Apodan, Copenhagen, Denmark), Sephadex G 75 gel (Pharmacia Fine Chemicals, Uppsala, Sweden), and zymosan A (Sigma, St Louis, USA) were employed. Rabbit antibodies to human $\mathrm{C} 3 \mathrm{c}$ and $\mathrm{C5}$ and rabbit immunoglobulins from non-immunised rabbits were from DAKO-immunoglobulins, Copenhagen, Denmark.

\section{CHEMOATTRACTANTS}

C5a was prepared from complement activated plasma according to proven principles. ${ }^{11}{ }^{12}$ Freshly drawn heparin plasma $(2 \mathrm{U} / \mathrm{ml})$, preincubated overnight with epsilon aminocaproic acid $(1 \mathrm{M})$ at $4^{\circ} \mathrm{C}$, was activated with zymosan $(20 \mathrm{mg} / \mathrm{ml})$ for 75 minutes at $37^{\circ} \mathrm{C}$. Activated plasma was fractionated on a column of Sephadex G 75 with Gey's solution including EDTA $(10 \mathrm{mM})$ as previously described. ${ }^{5}$ Fractions, with chemoattractant activity eluated in the MW 15000 region, were pooled, dialysed against Gey's solution, frozen in liquid nitrogen, and kept at $-70^{\circ} \mathrm{C}$ until analysis. Low molecular weight fractions prepared identically, except for the use of non-activated plasma, showed no chemoattractant activity. The specificity of C5a preparations was further tested by antibody incubation experiments. ${ }^{5}$ Activity was abolished in these experiments by antibody to $\mathrm{C} 5$ but not by immunoglobulins from non-immunised rabbits or by antibody to C3. Separation of pooled fractions from the native complement components, which is essential to prevent additional artifactual activation, was shown by fused rocket immunoelectrophoresis ${ }^{13}$ against antibody to complement component $\mathrm{C} 3$ and $\mathrm{C} 5$.

Casein $(5 \mathrm{mg} / \mathrm{ml})$ was dissolved in modified Gey's solution at $\mathrm{pH} 12$ according to Wilkinson. ${ }^{14}$

ASSESSMENT OF NEUTROPHIL MIGRATION

Leucocyte suspensions for chemotaxis were prepared from peripheral hlood drawn in EDTA
(10 mM). After methyl cellulose sedimentation of the red cells, leucocytes were washed three times and resuspended in Gey's solution including albumin $(20 \mathrm{mg} / \mathrm{ml})$ at a concentration of $2 \times 10^{6}$ cells $/ \mathrm{ml}$.

Migratory responses of neutrophils were assessed in Sartorius ${ }^{\circledR} 3 \mu \mathrm{m}$ pore size filters placed in modified Boyden chambers. ${ }^{14} \mathrm{C} 5 \mathrm{a}$ prepared by twofold dilutions in Gey's solution of pooled fractions from Sephadex chromatography and casein was applied as attractant. Spontaneous motility that is, non-activated migration - was assessed with Gey's solution in both chamber compartments.

Responses to a panel of two-fold C5a dilutions, to casein and spontaneous motility were measured by the leading front method ${ }^{15}$ after an incubation period of 30 minutes for C5a chemotaxis and spontaneous motility and 60 minutes for response to casein. Sensitivity to C5a was expressed in titres of C5a corresponding to a half peak response. Such titres were calculated by linear intrapolation in the ascending part of individual dose response curves after subtraction of values for spontaneous migration. Median migration rates were calculated by linear intrapolation of cell distribution curves in filters. Curves were based on cell counts in $10 \times 400$ fields at fixed depths in filters: 5, 15, 25, $35 \mu \mathrm{m}$ etc.

STATISTICS

The Mann-Whitney rank sum test and the Spearman rank correlation test were applied.

\section{Results}

Representative dose response curves for C5a activation of neutrophil migration are given for healthy volunteers, patients with Crohn's disease, and patients with ulcerative colitis (Fig. 1). Responses increased with increasing concentration of C5a to reach a peak value in all tests. Further increases of activator concentration lead to a decline of migration rates.

Sensitivity to C5a was expressed in titres corresponding to half peak response. Median values were 


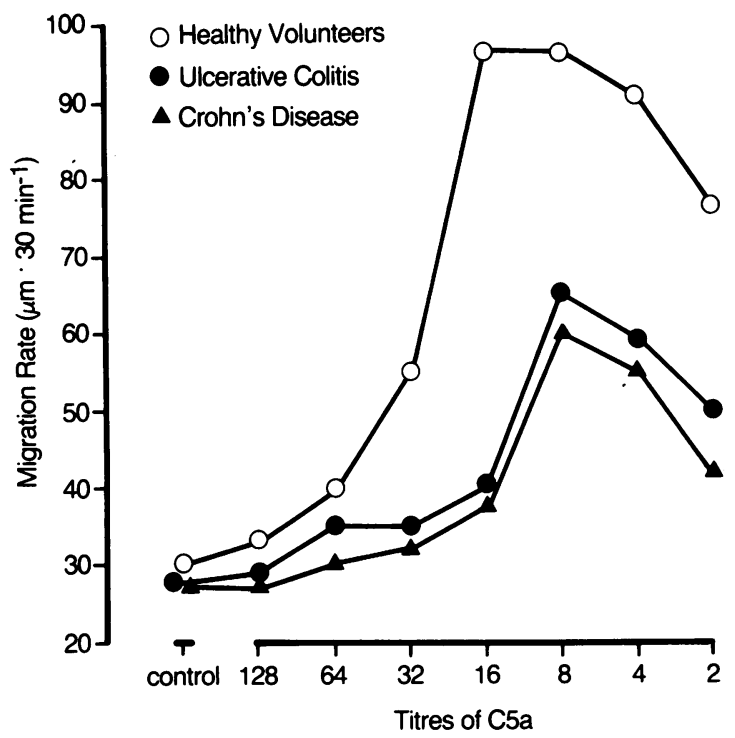

Fig. 1 Representative dose response curves for neutrophil chemotaxis to C5a in patients with Crohn's disease, patients with ulcerative colitis, and healthy volunteers. Migration was activated by two-fold dilutions of C5a or was assessed in the absence of attractant (control).

13 in ulcerative colitis and Crohn's disease patients and 26 in controls (Fig. 2). This two-fold decrease of sensitivity was significant at the 0.005 level in both groups of patients. Peak responses were slightly subnormal in Crohn's disease (median $67 \mu \mathrm{m} / 30$ min, $\mathrm{p}<0.025$ ) and ulcerative colitis (median $70 \mu \mathrm{m} / 30 \mathrm{~min}, \mathrm{p}<0.025)$ patients compared with healthy volunteers (median $92 \mu \mathrm{m} / 30 \mathrm{~min}$ ) (Fig. 3). Spontaneous, non-activated motility ranged from $20-43 \mu \mathrm{m} / 30 \mathrm{~min}$ and did not show differences between patients and controls.

Significant decreases of sensitivity and peak response to C5a were found in patients in complete clinical remission and in active stages of chronic inflammatory bowel disease $(\mathrm{p}<0 \cdot 05)($ Table 2$)$. A trend for a more severely depressed peak response in active stages of the disease did not reach statistical significance $(p>0 \cdot 10)$. Data for patients with Crohn's disease and ulcerative colitis showed no differences and were pooled in Table 2.

Chemotaxis to casein did not differ between healthy volunteers (median $75 \mu \mathrm{m} / 60 \mathrm{~min}$ ), patients with Crohn's disease (median $77 \mu \mathrm{m} / 60 \mathrm{~min}$ ), and ulcerative colitis (median $77 \mu \mathrm{m} / 60 \mathrm{~min})(\mathrm{p}>0 \cdot 10)$ (Fig. 4).

Dose response curves and responses to casein were assessed by the leading front method. This parameter of neutrophil function may not be representative for the whole population of migrating

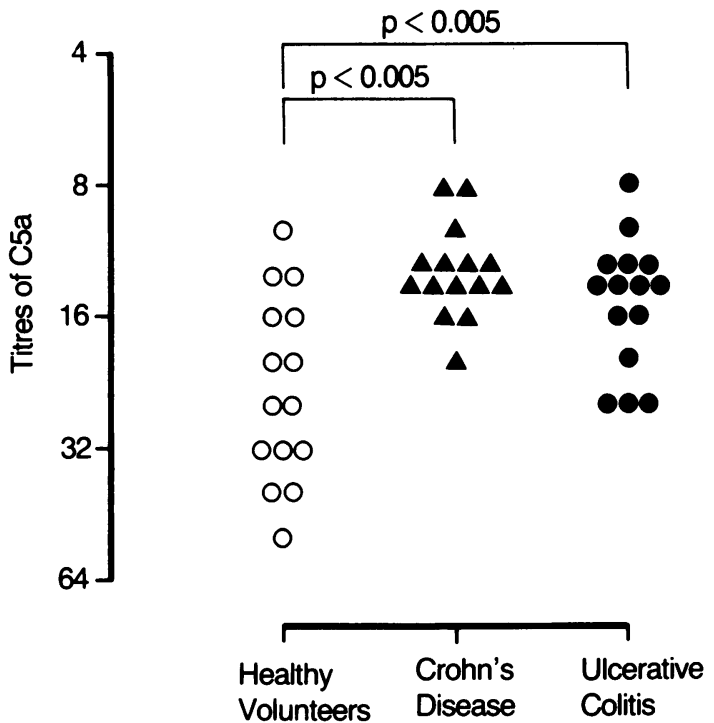

Fig. 2 Titres corresponding to a half maximal C5a response were decreased in Crohn's disease and ulcerative colitis compared with healthy volunteers $(p<0.005)$.

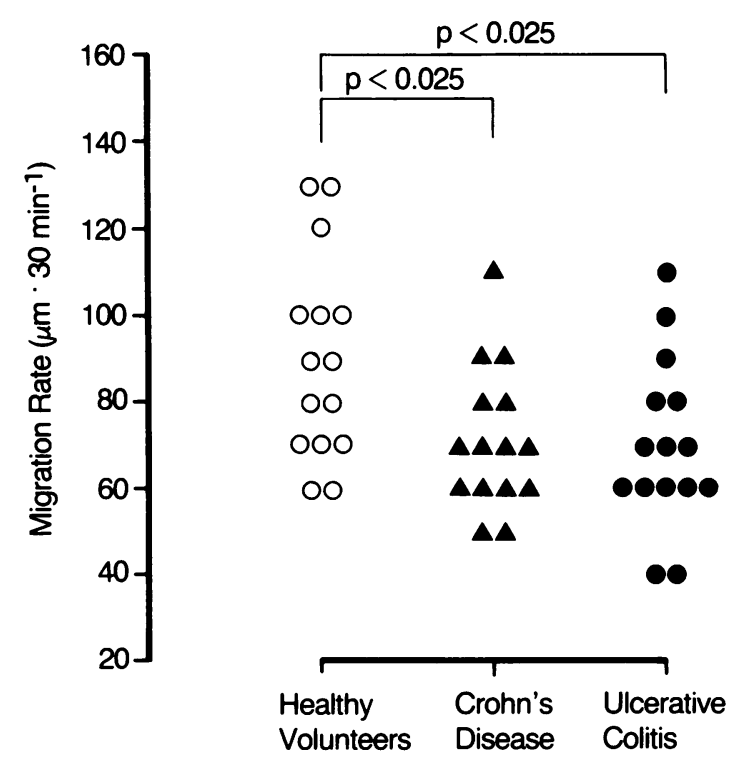

Fig. 3 Peak responses to C5a were slightly subnormal in Crohn's disease and ulcerative colitis compared with healthy volunteers $(p<0 \cdot 025)$. 
Table 2 Relation of neutrophil function to disease activity in chronic inflammatory bowel disease

\begin{tabular}{|c|c|c|c|}
\hline \multirow[b]{2}{*}{ Group } & \multirow[b]{2}{*}{ Disease activity } & \multicolumn{2}{|c|}{ Response to $C 5 a^{*}$} \\
\hline & & $\begin{array}{l}\text { Peak response } \\
(\mu \mathrm{m} / 30 \mathrm{~min})\end{array}$ & $\begin{array}{l}\text { Half maximal } \\
\text { C5a titre }\end{array}$ \\
\hline $\begin{array}{l}\text { Crohn's disease and ulcerative colitis } \\
\text { Healthy volunteers }\end{array}$ & $\begin{array}{l}\text { Active stages }(n=18) \\
\text { Complete remission }(n=12) \\
(n=15)\end{array}$ & $\begin{array}{l}59(31-108) \\
72(58-95) \\
92(60-133)\end{array}$ & $\begin{array}{l}13(10-26) \\
13(8-26) \\
26(10-52)\end{array}$ \\
\hline
\end{tabular}

* Median values are given with ranges in parentheses.

Peak response and half maximal C5a titre were significantly decreased in both subgroups of IBD patients $(p<0 \cdot 05)$.

neutrophils. To test this possibility leading front values were compared with median migration rate at C5a titres yielding a peak response in individual dose response curves. A highly significant correlation $\left(r_{s}=0.77, p<0.0005, n=45\right)$ could be established between the two parameters of cellular function (Fig. 5). Peak responses assessed by median migration rates were decreased in Crohn's disease (median $14 \mu \mathrm{m} / 30 \mathrm{~min}$ ) and ulcerative colitis (median $14 \mu \mathrm{m} / 30 \mathrm{~min}$ ), compared with healthy volunteers (median $20 \mu \mathrm{m} / 30 \mathrm{~min})(\mathrm{p}<0.025)$.

Cell suspensions prepared for chemotaxis contained approximately $70 \%$ neutrophils, and the recovery of neutrophils was $70 \%$ (Table 3 ).

\section{Discussion}

Investigation of phagocytic cell function in IBD patients may be important for understanding the

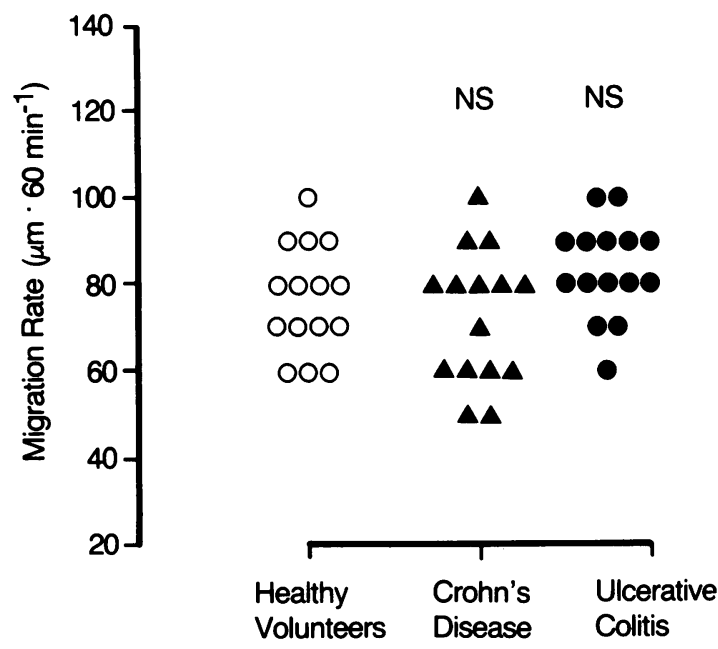

Fig. 4 Chemotaxis to casein did not differ between groups of patients and healthy volunteers $(p>0 \cdot 10)$. pathogenesis of the disease. In chronic granulomatous disease a dysfunction of neutrophils can produce histologic changes of the gut closely resembling those seen in Crohn's disease. ${ }^{16}$ Previous investigations of neutrophil chemotaxis in IBD have shown an essentially normal response to the nonphysiologic attractant casein. ${ }^{5-7}$ The present study confirms this finding showing a normal basic cell function but has revealed specific changes of neutrophil activation by complement. Analysis of dose response curves showed that sensitivity to C5a was decreased by a factor of two in patients both with Crohn's disease and ulcerative colitis. This abnormality could not be overcome by increasing the concentration of activator, leading to a depression of responses. Peak migration rates obtained by the panel of C5a concentrations tested were furthermore similarly decreased in both groups of patients.

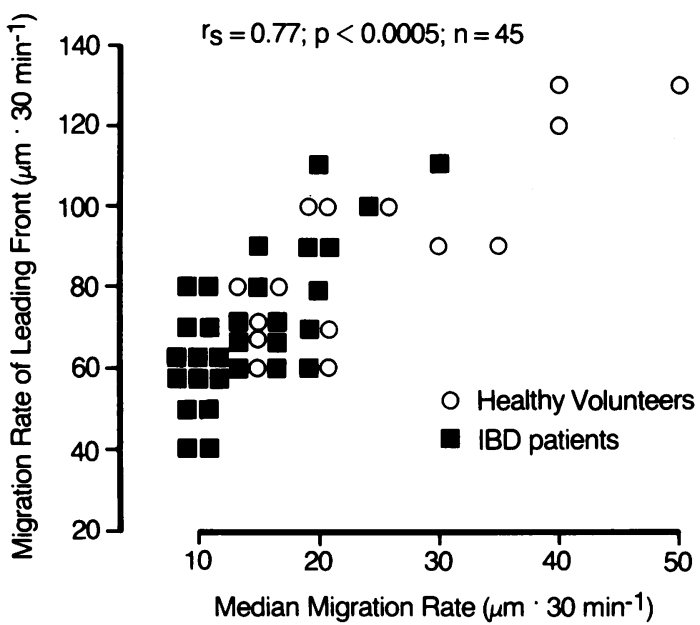

Fig. 5 Peak response to C5a as assessed by the leading front method correlated positively with corresponding values of median migration rate $\left(r_{s}=0.77 ; p<0.0005\right.$; $n=45$ ). 
Table 3 Recovery of neutrophils and purity of cell suspensions for chemotaxis

\begin{tabular}{llll}
\hline & & \multicolumn{2}{l}{$\begin{array}{l}\text { Neutrophils in cell } \\
\text { suspension }\end{array}$} \\
\cline { 2 - 4 } \cline { 3 - 4 } Patient group & No & $\begin{array}{l}\text { Purity } \\
\%\end{array}$ & $\begin{array}{l}\text { Recovery } \\
\%\end{array}$ \\
\hline Crohn's disease & 15 & $76(68-85)$ & $71(57-90)$ \\
Ulcerative colitis & 15 & $73(60-84)$ & $75(57-87)$ \\
Healthy volunteers & 15 & $72(61-86)$ & $69(43-88)$ \\
\hline
\end{tabular}

* Median values with ranges in parentheses.

No significant differences could be detected between patients and healthy volunteers $(p>0 \cdot 10)$.

Interaction of C5a with a specific cellular receptor has previously been shown to be essential for stimulation of chemotaxis and lysosomal enzyme release in human polymorphonuclear leucocytes. ${ }^{17}$ Both primary and secondary defects of this C5a receptor may explain our results. It seems to be suggestive that activation of complement in haemodialysis and exposure of neutrophils to $\mathrm{C} 5 \mathrm{a}$ during in vitro conditions induce a similarly decreased C5a chemotaxis of the cells whereas responses to casein remains unaffected. ${ }^{18}$ Moreover, the normal activation of neutrophils by casein in the present patients is important as the casein chemotaxis method has proved to be reliable for detecting intrinsic defects of the cellular function in leukaemia. ${ }^{19}$ Continuous activation of complement in IBD has been suggested by unrelated immunologic techniques. ${ }^{2-4}$ Activation may lead to specific desensitisation of circulating neutrophils in a manner similar to that obtained in haemodialysis. Further substantiation for the alternative hypothesis of a primary defect of the C5a receptors of IBD patients could potentially be provided by investigating close relatives of the patients.

A decreased activation of neutrophil chemotaxis by C5a may contribute to the well established, severely depressed migration of neutrophils into skin window chambers in Crohn's disease. ${ }^{20-22}$ In ulcerative colitis, on the contrary, migration of neutrophils in skin windows is either less markedly decreased $^{6}$ or within the normal range ${ }^{23}$ depending on the experimental conditions. This discrepancy of results obtained in ulcerative colitis and Crohn's disease indicates that the decreased response of neutrophils to C5a cannot in itself explain the skin window results. Changes of humoral factors may participate in this abnormality. Accordingly, serum inactivators of $\mathrm{C} 5 \mathrm{a}$ occur in increased concentrations in IBD, particularly in Crohn's disease, ${ }^{24}$ and may be essential for the behaviour of inflammatory neutrophils. A decreased function of alternative pathway complement ${ }^{525}$ reflected in a subnormal release of C5a during cascade activation ${ }^{5}$ has been shown in Crohn's disease but only in a subgroup of ulcerative colitis patients with complicating extraintestinal manifestations. It thus seems as if several factors may be responsible for the obviously decreased primary inflammatory response of neutrophils in IBD patients.

A dysfunction of phagocytes may delay the clearance of foreign macromolecules which are known to penetrate the gut mucosa even during physiologic conditions. Persistence of such material could be a potent stimulus for perpetuation of inflammation by, for instance, activating complement reactions. In cases of complete clinical remission a persistently decreased capacity for activation of neutrophil functions by the complement split product $\mathrm{C5a}$ may predispose to later clinical relapses.

The study was supported by a grant from Johann and Hanne Weimann neé Sedorff's foundation. Helma Furhauge and Hanne Kargaard are thanked for excellent technical assistance and Lise Nielsen for typing the manuscript.

\section{References}

1 Atkinson JP, Frank MM. Complement. In: Parker CW, ed. Clinical immunology. Philadelphia, London, Toronto: Saunders, 1980.

2 Hodgson HJF, Potter BJ, Jewell DP. C3 metabolism in ulcerative colitis and Crohn's disease. Clin Exp Immunol 1977; 28: 490-5.

3 Elmgreen J, Berkowicz A, Sørensen H. Hypercatabolism of complement in Crohn's disease - assessment of circulating C3c. Acta Med Scand 1983; 214: 403-7.

4 Potter BJ, Brown DJC, Watson A, Jewell DP. Complement inhibitors and immunoconglutinins in ulcerative colitis and Crohn's disease. Gut 1980; 21: 1030-4.

5 Elmgreen J, Berkowicz A, Sørensen H. Defective release of $\mathrm{C} 5 \mathrm{a}$ related chemo-attractant activity from complement in Crohn's disease. Gut 1983; 24: 525-31.

6 Wandall $\mathrm{JH}$, Binder V. Leucocyte function in ulcerative colitis. Gut 1982; 23: 758-65.

7 Rhodes JM, Jewell DP. Motility of neutrophils and monocytes in Crohn's disease and ulcerative colitis. Gut 1983; 24: 73-7.

8 Binder V, Both H, Hansen PK, Hendriksen C, Kreiner $S$, Torp-Pedersen $K$. Incidence and prevalence of ulcerative colitis and Crohn's disease in the county of Copenhagen, 1962-1978. Gastroenterology 1982; 83: 563-8.

9 Harvey RF, Bradshaw JM. A simple index of Crohn's disease activity. Lancet 1980; 1: 544.

10 Binder V. A comparison between the clinical state, 
macroscopic and microscopic appearances of rectal mucosa and cytologic picture of mucosal exudate in ulcerative colitis. Scand J Gastroenterol 197(); 5: 62732.

11 Vallota EH, Müller Eberhardt HJ. Formation of C3a and C5a anaphylatoxins in whole human serum after inhibition of the anaphylatoxin inactivator. J Exp Med 1973; 137: 11(1)9-23.

12 Goldstein IM, Roos D, Kaplan HB, Weismann G. Complement and immunoglobulins stimulate superoxide production by human leucocytes independently of phagocytosis. J Clin Invest 1975; 56: 1155-63.

13 Svendsen PJ. Fused rocket immunoelectrophoresis. In: Axelsen NH, Kröll J, Weeke B, eds. A manual of quantitative immunoelectrophoresis. Oxford, London, Edinburgh, Melbourne: Blackwell Scientific Publication, 1977.

14 Wilkinson PC. Chemotaxis and inflammation. Edinburgh: Churchill Livingstone, 1974.

15 Zigmond SH, Hirsch JG. Leucocyte locomotion and chemotaxis. J Exp Med 1973; 137: 387-411.

16 Ament ME, Ochs HD. Gastrointestinal manifestations of chronic granulomatous disease. N Engl J Med 1973; 288: $382-7$.

17 Chenoweth DE, Hugli TE. Demonstration of a specific C5a receptor on intact human polymorphonuclear leucocytes. Proc Natl Acad Sci USA 1978; 75: 3943-7.

18 Skubitz KM, Craddock PR. Reversal of hemodialysis granulocytopenia and pulmonary leucostasis - a clinical manifestation of selective down-regulation of granulocyte response to $\mathrm{C}^{\mathrm{a}} \mathrm{a}_{\mathrm{de}}$ arg. J Clin Invest 1981; 67: 1383-91.

19 Pedersen Bjerregaard J, Vindeløv L, Philip P et al. Varying involvement of peripheral granulocytes in the clonal abnormality - 7 in bone marrow cells in preleucaemia secondary to treatment of other malignant tumours. Cytogenetic results compared with results of flow cytometric DNA-analysis and neutrophil chemotaxis. Blood 1982; 60: 172-9.

20) Segal AW, Loevi G. Neutrophil dysfunction in Crohn's disease. Lancet 1976; 2: 219-21.

21 Morain CO, Segal AA, Walker D, Levi AJ. Abnormalities of neutrophil function do not cause the migration defect in Crohn's disease. Gut 1981; 22: 817-22.

22 Wandall JH, Binder V. Leucocyte functions in Crohn's disease. Gut 1982; 23: 173-80.

23 Elmgreen J, Binder V. The chemotactic function of neutrophils in ulcerative colitis. Scand J Gastroenterol 1982; 17: 561-4.

24 Rhodes JM, Potter BJ, Brown DJT, Jewell DP. Serum inhibitors of leucocyte chemotaxis in Crohn's disease and ulcerative colitis. Gastroenterology 1982; 82: 132734.

25 Lake AM, Stitzel AE, Urmson JR, Walker WA, Spitzer RE. Complement alterations in inflammatory bowel disease. Gastroenterology 1979; 76: 1374-9. 